\title{
ETV add-on Peg-interferon therapy plays a positive role in reversing hepatic fibrosis in treatment-naïve chronic hepatitis B patients: a prospective and randomized controlled trial
}

\section{Jingmao Yang}

Shanghai Public Health Clinical Center https://orcid.org/0000-0002-5026-5301

\section{Liping Chen}

Shanghai Public Health Clinical Center

\section{Yajie Wang}

Shanghai Public Health Clinical Center

Bei Lv

Zhongshan Hospital Fudan University

\section{Hong Zhao}

Dongyang People's Hospital

\section{Zhiyin Shang}

Shanghai Public Health Clinical Center

Jun Li

Shanghai Public Health Clinical Center

\section{Zhenyu Fan}

Shanghai Public Health Clinical Center

\section{Shaoping Huang}

Shanghai Public Health Clinical Center

Jilin Cheng ( $\square$ chengjilin@shphc.org.cn )

\section{Research article}

Keywords: peg-interferon, entecavir (ETV), chronic hepatitis B, curative effect, combination therapy

Posted Date: August 29th, 2019

DOI: https://doi.org/10.21203/rs.2.12909/v1

License: (c) This work is licensed under a Creative Commons Attribution 4.0 International License. Read Full License 


\section{Abstract}

Background and Aim The efficacy of entecavir (ETV) add-on peg-interferon therapy compared with ETV monotherapy in treatment-naïve hepatitis B virus (HBV) patients remains controversial. We investigated whether adding Peg-interferon to ongoing ETV treatment leads to a better curative effect or not. Methods Eligible HBV patients $(n=144)$ were randomly divided (1:1) to receive either ETV monotherapy $(n=70)$ or peg-interferon add-on therapy from weeks 26 to $52(n=74)$. Patients were followed-up for 2 years. We evaluated hepatitis B surface antigen (HBsAg) and hepatitis B e antigen (HBeAg) seroconversion rate, sustained virologic response (SVR), transient elastography value, and histological scores. Results At week 26, no patient achieved HBsAg seroconversion in either group. At week 52, one patient in the monotherapy group was HBsAg-negative but there was none in the combination therapy group. The monotherapy group showed significantly better liver function recovery results than the combination therapy group. At week 78 , one patient in combination group had HBsAg seroconverted. At week 104, only three patients in the combination therapy group were HBsAg-negative compared with one patient in monotherapy. The mean alanine aminotransferase (ALT)and aspartate aminotransferase (AST) levels and transient elastography values decreased significantly compared with baseline. Both group showed a favorable decrease in alpha fetoprotein(AFP) (monotherapy:23.4 \pm 77.3 vs 2.4 $\pm 0.91, P=0.149$; combination therapy: $33.3 \pm 96.9$ vs $4.3 \pm 5.5, P=0.085$ ) and an improved result of liver biopsy examination scores. The combination group showed a better improvement in histology compared with the monotherapy group(mean transient elastography value $7.5 \pm 3.4 \mathrm{kPa}$ [SD 1.9] vs. $12.8 \pm 13.9 \mathrm{kPa}$ [SD 1.9], $\mathrm{P}=0.037)$. But this research didn't show significant difference in HBsAg conversion rate (1.79\% (1/56) vs 4.11\% (3/73), $\mathrm{P}=0.632)$ as well as HBV-DNA sustained virologic response( $93.2 \%$ vs $98.5 \%, P=0.15)$ between two groups. Conclusions Both therapies supported liver function recovery and histology improvement. Combination therapy did not show better antiviral efficacy in HBsAg or HBeAg seroconversion compared with monotherapy. However, combination therapy played a more positive role in reversing hepatic fibrosis compared with monotherapy.

\section{Background}

There are approximately 240 million patients infected with Hepatitis B virus $\varangle \mathrm{HBV} \bigotimes$ worldwide, which represents a challenge to public health despite clinical application of new drugs and efficacious vaccines ${ }^{1,2}$.Nucleos(t)ide analogues (NAs) are used more commonly in HBV treatment protocols because they can suppress HBV-DNA replication, help to recover liver function, improve histology, and obtain a functional cure which defined as hepatitis $B$ surface antigen(HBsAg)-negative regardless of the presence or absence of (hepatitis B surface antibody) HBsAb. However longterm NAs therapy may also cause drug-resistant mutations. Peg-IFNa-2a is an immune-modulating drug that can induce cytotoxic T-cells, which clears the HBV virus from infected cells through the immunomodulatory pathway and reduces the covalently closed circularDNA(cccDNA)levels ${ }^{3,4}$.Peg-IFNa-2a was shown to achieve a higher rate of HBeAg seroconversion and HBsAg seroclearance compared with entecavir (ETV) treatment ${ }^{5,6}$. Combination therapy of lamivudine (LAM) and peg-IFNa-2a showed a higher virologic response rate but there was no improvement in the sustained virologic response (SVR) compared with monotherapy ${ }^{7}$. However, peg-IFNa-2a has several disadvantages including a moderate antiviral effect, sustained risk of adverse events, inferior tolerability, and subcutaneous injections. What's more囚it requires regular clinical follow-up visits and a strict administration schedule. Therefore, NAs and pegIFNa-2a combination therapy has been carried out to find an optimal efficacy, but the results of these trials are controversial because of the varying designs and evaluation criteria ${ }^{8-10}$. Some studies considered that combination therapy was better than monotherapy, but antiviral therapeutic options are largely influenced by the cost of drugs in China $^{11}$. Most treatment-naïve patients generally start on NAs as an initial treatment because they are inexpensive and have a confirmed curative effect despite drug resistance. 
Therefore, we designed this prospective trial to evaluate the curative effect of adding peg-interferon to ongoing ETV therapy in treatment-naïve patients. Given the side effects of peg-IFNa-2a monotherapy and drug-resistance of ETV long-term therapy, we evaluated whether shortening the add-on course(26 weeks) of peg-IFNa-2a improve outcomes such as enhancing virologic response and SVR or not.

\section{Methods}

\section{Study design}

Eligible participants were randomly divided into two groups at the start of the study by using a computerized randomization program. 144 eligible patients were randomly divided, in a 1:1 ratio, to receive either ETV monotherapy (n $=70$ ) or Peg-interferon add-on therapy $(n=74)$. Both groups were given ETV for 2 years, but after 26 weeks, the combination therapy group received additional peg-IFN once weekly from week 26 to week 52 . The efficacy of NAs monotherapy and combination therapy was compared every 3 months until the end of the study. Liver histology was also evaluated when participants were enrolled into the trial and after 2 years of therapy. They underwent a liver biopsy at the beginning and end of study.

\section{Inclusion and exclusion criteria}

This randomized controlled trial was approved by legally instituted ethics committees at Shanghai Public Health Clinical Center and Zhongshan Hospital. All chronic HBV patients were positive for HBsAg and had an HBV-DNA viral load >500 $\mathrm{IU} / \mathrm{mL}$ with two consecutive tests at least 6 months apart, and the patients were treatment-naïve. Patients who were either HBeAg-positive or negative were included. Exclusion criteria were as follows: 1) co-infected with hepatitis A virus, hepatitis $C$ virus, hepatitis $D$ virus, or human immunodeficiency virus; 2) decompensated liver disease or a history of esophageal varices; 3) hepatocellular carcinoma; 4) pregnancy or lactation, or liver transplantation; 5) alcoholic hepatitis, drug hepatitis, autoimmune disease, or metabolic liver disease; 6) comorbidities such as diabetes mellitus, arterial hypertension, dyslipidemia, coronary artery diseases, thyropathy. All patients signed an informed consent for indicating that their participation was voluntary and that their samples could be used for research. They were also informed of adverse events. The trial design is shown in Fig. 1.

\section{Measurements}

Before participants were enrolled in the trial, laboratory tests and routine examinations were performed at 3-month intervals for 6 months. Serum HBsAg and HBeAg levels were tested by Architect i2000 analyzer (Abbott Diagnostics, Abbott Park, IL, USA; HBsAg range of 0.05 to $52,000 \mathrm{lU} / \mathrm{mL}$ and HBeAg cut-off index $<10 \mathrm{~m} \mathrm{IU} / \mathrm{mL}$ ), HBV DNA were amplified using the iCycler device (Bio-Rad, USA; lower limit of quantification: $500 \mathrm{IU} / \mathrm{mL}$ ). Liver biopsies were assessed at Zong Shan Hospital and Shanghai Public Health Clinical Center, Fudan University, Shanghai, China.

\section{Evaluation criteria}

$\mathrm{HBsAg} / \mathrm{HBeAg}$, serum HBV-DNA viral load, and liver function were assessed at the beginning of treatment. The rate of patients with HBsAg loss was defined as the primary endpoint. SVR means sustained suppression of undetecable HBV DNA. The proportion of patients with a SVR, HBeAg seroconversion loss or seroconversion, histology improvement, and liver function were defined as secondary endpoints. HBsAg loss refers to undetectable serum $\mathrm{HBsAg}<0.05 \mathrm{IU} / \mathrm{mL}$, and $\mathrm{HBsAg} / \mathrm{HBeAg}$ seroconversion means the detectable HBeAb /HBsAb antibodies. HBV-DNA< $500 \mathrm{IU} / \mathrm{mL}$ was defined as 
an undetectable level. Ishak score was evaluated by professional pathologist. A reduction in the Ishak score or thetransient elastography score between the first day of treatment and the end of therapy was defined as the histology improvement criterion. We Analyzed HBsAg/HBeAg loss or seroconversion, viral load, and liver function every 3 months and the end of treatment between the two groups. Adverse events were also recorded in both groups.

\section{Statistical analysis}

All statistical analyses were processed using the SPSS version 19 (SPSS Inc. Chicago, IL, USA). Continuous variables were compared using the Student's $t$-test and categorical data were presented as $\mathrm{n}(\%)$. The $\mathrm{HBsAg} / \mathrm{HBeAg}$ seroconversion rate between the two groups was compared using the Chi-square test. A $P$ value of $<0.05$ was defined as statistically significant.

\section{Results}

\section{Baseline characteristics}

All baseline characteristics of the two groups are shown in Table 1. Almost all clinical data from the two groups were comparable. All patients were HBsAg positive, with an HBV viral load $>500 \mathrm{IU} / \mathrm{ml}$, no participant had liver cirrhosis.

\section{Clinical efficacy of two groups}

The clinical efficacy was different between the two groups at different time points, as shown in Table 2. Baseline and endpoint treatment variables were also compared in each group (Table 3). These results indicated that at week 52, the monotherapy group had better liver function recovery compared with the add-on treatment group (ALT: $26.0 \pm 12.1 \mathrm{U} / \mathrm{L}$ vs. 37.4 $\pm 34.4, P=0.029$; AST: $26.8 \pm 7.0 \mathrm{U} / \mathrm{L}$ vs. $36.4 \pm 23.6 \mathrm{U} / \mathrm{L}, P=0.007)$, but there was no significant difference in ALT and AST levels between the two groups at week 104. The results also showed that the monotherapy group might have favorable AFP decrease compared with the combination therapy group $(2.4 \pm 0.84 \mathrm{ng} / \mathrm{mL}$ vs. $4.7 \pm 5.7 \mathrm{ng} / \mathrm{mL}, P=0.011)$. At the end of 2 years, the mean ALT and AST levels and the transient elastography value decreased significantly in each group compared with baseline data.

\section{HBsAg/HBeAg clearance or seroconversion results}

At week 26, patients in both groups only received ETV for treatment, and none of them showed HBsAg loss, whereas some patients began to lose and/or seroconvert HBeAg.

At week 52, one patient in the monotherapy group but none in the combination therapy group had lost HBsAg. In both groups, another three patients had lost and/or seroconverted HBeAg. The patient who had lost HBsAg in the monotherapy group also had an undetectable HBV viral load, but his liver function test results remained abnormal during the treatment. Additionally, before receiving ETV monotherapy treatment, the patient had already been followed-up in our department for 2 years with slightly high ALT and AST levels and HBV viral load.

At week 78, one patient from combination group had lost and/or seroconverted HBsAg.

At the end of our study, there was altogether one patient who lost HBsAg in the monotherapy group while three patients in the combination therapy group showed HBsAg clearance $(1.79 \%(1 / 56)$ vs $4.11 \%(3 / 73), P=0.632)$. All data are presented in Table 4. Additionally, Figure 2A and 2B provide supplementary information about the total number of 
patients who lost HBsAg, HBeAg and/or seroconverted with the respective antibody formation at different time points. Data are presented as $\mathrm{n}(\%)$. Figure $2 \mathrm{C}$ shows the change of HBsAg levels. Figure 2D presents the results of SVR. There was no significant difference in SVR between the two groups.

\section{Complementary liver histology results}

Combination therapy showed better histology improvement than the monotherapy group (mean liver stiffness value $7.5 \pm 3.4 \mathrm{kPa}$ [SD 1.9] vs. $12.8 \pm 13.9 \mathrm{kPa}$ [SD 1.9], $\mathrm{P}=0.037$ ). The liver stiffness value decreased significantly in each group compared with baseline data. Liver histology improved remarkably in both groups after 2 years. The results are shown inFigs 3 and 4.

\section{Adverse events}

During treatment, three patients showed thyroid dysfunction (one patient in monotherapy) and two patients had granulopenia (both in the combination therapy group). Six patients had a fever in the combination therapy group after they received their treatment. One patient felt fatigue in the ETV monotherapy group.

\section{Discussion}

In present, various therapies have been proceeded for $\mathrm{CHB}$, but the optimal regimen remains unclear. The clinical cure rate of combined treatment with NAs and peg-IFN is not sufficient to treat naïve chronic hepatitis B patients. peg-IFN monotherapy was also found to be efficient for HBsAg loss and seroconversion, but combination therapy was thought to cause more adverse events ${ }^{12-13}$. However, other studies have reported that the therapeutic efficacy of NAs combined with peg-IFN was better than monotherapy ${ }^{14}$.NAs are thought to directly inhibit HBV DNA replication, while peg-IFNa-2a as an immunomodulator can enhance the innate and adaptive immune responses to play a synergistic antiviral role $\mathrm{e}^{15}$, ${ }^{16}$.In Yan's study ${ }^{11}$, addition of NAs to peg-IFNa-2a therapy enhanced the virologic response in chronic hepatitis $\mathrm{B}$ patients who did not have an early response to peg-IFNa-2a.This suggests that in patients with an early poor virologic response to Peg-IFNa-2a, addition of NAs could inhibit viral replication. An trial directed by Ning also found that patients who switched from entecavir to peg-IFNa-2a significantly had increased rates of $\mathrm{HBeAg}$ seroconversion and $\mathrm{HBsAg}$

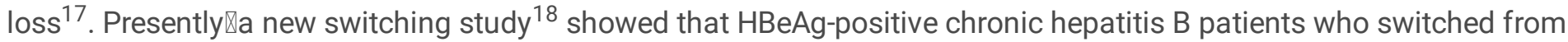
NAs to pegylated interferon achieved $12.5 \%$ and $16.2 \%$ HBeAg seroconversion and HBsAg loss, respectively. In a recent study, Patients on long-term NA who are unlikely to meet therapeutic goals can achieve high rates of HBsAg loss by switching to Peg-IFN alfa-2a ${ }^{19}$. It seems add-on therapy resulted in more viral decline and appeared to prevent relapse after stopping ETV compared with monotherapy. Therefore, based on this synergistic mechanism, combination therapy may be an ideal method for chronic HBV patients. However, we did not observe these results. In our study, we did not find a significant difference in clinical efficacy between the two groups, which is similar to other studies that reported that combination therapy failed to improve clinical efficacy ${ }^{20}$. However, a recent meta-analysis also showed that combination therapy increased the virologic response and $S V R^{8}$.Adding peg-IFNa-2a to ADV \adefovir dipivoxil囚or ETV showed better clinical efficacy in HBeAg-negative patients ${ }^{21}$.

In this randomized controlled trial, our results showed that combination therapy did not have better antiviral efficacy than ETV monotherapy for sustained virologic suppression, HBsAg/HBeAg clearance, and seroconversion, but its histologic results showed improvement in the combination group. Additionally, the rate of $\mathrm{HBsAg} / \mathrm{HBeAg}$ clearance and seroconversion was not different from combination therapy compared with ETV monotherapy after adding peg-IFNa-2a. But a recent retrospective cohort study ${ }^{22}$ showed that patients in the peg-IFN add-on therapy group were more likely to 
achieve HBeAg seroconversion (44\% vs. 6\%; P < 0.0001) compared with those in the ETV monotherapy group. The reason may be that the duration of the added peg-IFNa-2a administration was too short, and the different was not significant. Although some guidelines recommend 48 weeks of Peg-IFN administration for patients with chronic hepatitis B, we administered 26 weeks of peg-IFN add-on therapy because of the side effects and cost of the drug. Additionally, Brouwer WP 23 indicated that peg-IFN add-on therapy led to a higher proportion of HBeAg response compared with ETV monotherapy for HBeAg-positive chronic hepatitis B.The inclusion and exclusion criteria for patients may lead to differences in the outcomes.

In generally speaking, the sustained benefit of combination therapy requires further investigation. In our 2-year study, we compared the sustained efficacy between the two groups at different time points and we found that there was no significant difference between SVR in the two groups. However, this was not in consistent with the results of a recent study, which showed that combination therapy enhanced the virologic response and SVR ${ }^{7}$.The ideal result of anti-HBV therapy is HBsAg seroconversion, which often means a viral clearance. Achieving full viral clearance still remains a challenge. During the trial, three patients (two in the monotherapy group and one in the combination group) had hepatitis relapses even though their HBsAg was cleared and their viral load was undetectable during treatment. This phenomenon requires further study.

For histology improvement, we analyzed the transient elastography value and histological fibrosis score between the first day of treatment and the end of therapy. A significant difference in the transient elastography value was seen between the monotherapy and combination groups. The transient elastography value of combination groups decreased more than the monotherapy group. However, the ALT and AST recovery results were not in agreement with the transient elastography value. The monotherapy group had a tendency to have lower ALT $\square$ AST and lower AFP levels compared with combination therapy, but not the transient elastography results. Liver histology improved remarkably in each group after treatment for 2 years. Some studies showed that combination of peg-IFNa-2a may improve liver histology better than monotherapy by immunologically modulating activity of effector T-cells, which generate a robust cytotoxic $T$ lymphocyte (CTL) response ${ }^{24}$.CTLs can kill infected cells, so it results in an increase in transaminase levels. Additionally, it improved histology following long-term treatment. We also found that the AFP levels in the monotherapy group were lower than that in the combination group during the treatment. Lower post-treatment AFP levels were reported to be significantly correlated with liver fibrosis regression ${ }^{25}$.This phenomenon may be explained by the original baseline AFP levels in the combination therapy that were higher than those in the monotherapy group, although there is no significant difference between the two groups. Liver biopsy histological scores were evaluated at the end of the study, and the combination therapy was likely to have improved histology results compared with monotherapy, but the difference was not significant.

The most frequent adverse events reported in combination group were fatigue, headache, fever, and myalgia ${ }^{26-28}$. These adverse events were mostly related to adding Peg-IFNa-2a.As expected, more chronic hepatitis B patients taking combination therapy had side effects compared with those taking monotherapy in our study. Three patients had thyroid dysfunction, two patients had granulopenia, and one patient had fatigue in the ETV monotherapy. Therefore, attention must be paid to side effects of combination treatment.

There are some limitations in this trial, such as the small sample size, especially because some patients were lost to follow-up during treatment resulting from pregnancy, economic conditions, or the patient was unwilling to continue in the trial. However, the advantage of this study was that it was a randomized controlled perspective study. We evaluated the changes in ALT, AST, HBsAg/HBeAg clearance and seroconversion rate, and SVR at regular intervals, and we observed liver histological examination results. We also studied the effect of reducing the use time of interferon Peg-IFNa-2a.

\section{Conclusion}


For treatment-naïve patients with chronic hepatitis $B$, both monotherapy and combination therapy successfully improved liver function and histology. However, combination therapy did not show a better effect on HBsAg and HBeAg clearance and seroconversion or satisfactorily reduce HBV-DNA to an undetectable level. Our data also showed that combination therapy played a more positive role in reversing hepatic fibrosis than did monotherapy, but the safety of combination therapy requires further study. The curative effect of combination therapy and monotherapy also requires further study.

\section{Abbreviations}

ETV entecavir

HBsAg hepatitis B surface antigen

HBeAg hepatitis B e antigen

SVR sustained virologic response

ALT alanine aminotransferase

AST aspartate aminotransferase

HBV hepatitis B virus

NAs Nucleos(t)ide analogues

HBsAb hepatitis B surface antibody

cccDNA covalently closed circularDNA

LAM lamivudine

TBil total bilirubin

AFP alpha-fetoprotein

PLT platelet

ADV adefovir dipivoxil

\section{Declarations}

Availability of data and material

I'm sorry the data and material were not applicable, because this study is still going on.

Acknowledgements

We are grateful to the patients whom enrolled in this study. Authors are very appreciative for the cooperation extended by all the team members.

Funding

This study was funded by Major Science and Technology Special Project of China thirteenth 
Five-year Plan囚2013ZX10002004 and 2017ZX10203202-003-007凶खand it was the major supporting found which deigned the study \provided drugs and played a role in collecting data. Shanghai science and technology development

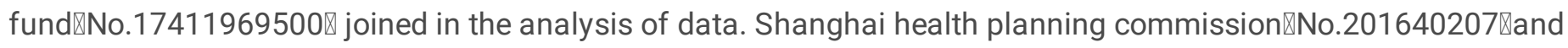
Chinese foundation for hepatitis prevention and control-TianQing liver disease research fund subject(TQGB20170158) joined in interpretation of data. Shanghai public health clinical center fund(KY-GW-2017-22) joined in writing the manuscript.All authors declare no conflict of interest.

Authors' contributions

All authors participated in conceiving and planning the study, YJM $\triangle C L P, W Y J, B e i$ Lv, ZH, SZY, LJ $\varangle F Z Y$ collected and analyzed the data. YJM $₫$ CLP drafted the manuscript. HSP $\mathbb{C}$ CJL did critical revision of manuscript. All authors contributed to final critical revision of the manuscript, and have read and approved the final manuscript.

Ethics approval and consent to participate

This study was conducted in compliance with the Declaration of Helsinki and approved by the Ethical Committee of Shanghai Public Health Clinical Center (2016-S026-04). All patients provided written documentation of informed consent to enter the study.

Consent for publication

Not applicable.

Competing interests

The authors declare that they have no competing interests.

\section{Reference}

1. Guidelines for the Prevention, Care and Treatment of Persons with Chronic Hepatitis B Infection. WHO Guidelines Approved by the Guidelines Review Committee. Geneva2015.

2.Al Therwani S, Rosenbaek JB, Mose FH, Bech JN, Pedersen EB. Effect of tolvaptan on renal water and sodium excretion and blood pressure during nitric oxide inhibition: a dose-response study in healthy subjects. BMC nephrology. 2017;18(1):86.

3.Boeijen LL, Hoogeveen RC, Boonstra A, Lauer GM. Hepatitis B virus infection and the immune response: The big questions. Best practice \& research Clinical gastroenterology. 2017;31(3):265-72.

4.Chuaypen N, Sriprapun M, Praianantathavorn K, et al. Kinetics of serum HBsAg and intrahepatic cccDNA during pegylated interferon therapy in patients with HBeAg-positive and HBeAg-negative chronic hepatitis B[J]. J Med Virol, 2017, 89(1): 130-138.

5.Liem KS, van Campenhout MJH, Xie Q, et al. Low hepatitis B surface antigen and HBV DNA levels predict response to the addition of pegylated interferon to entecavir in hepatitis B e antigen positive chronic hepatitis $B[\mathrm{~J}]$. Aliment Pharmacol Ther, 2019, 49(4): 448-456.

6.Sonneveld MJ, Zoutendijk R, Hansen BE, Janssen HL. Pegylated interferon results in higher serological, but not virological, response rates when compared to continuous entecavir. Antiviral therapy. 2012;17(8):1605-8. 
7.Marcellin P, Lau GK, Bonino F, Farci P, Hadziyannis S, Jin R, et al. Peginterferon alfa-2a alone, lamivudine alone, and the two in combination in patients with HBeAg-negative chronic hepatitis B. The New England journal of medicine. 2004;351(12):1206-17.

8.Zhou J, Wu X, Wei W, You H, Jia J, Kong Y. A Meta-Analysis of the Efficacy of Interferon Monotherapy or Combined with Different Nucleos(t)ide Analogues for Chronic Hepatitis B. International journal of environmental research and public health. 2016;13(5).

9.Vigano M, Invernizzi F, Grossi G, Lampertico P. Review article: the potential of interferon and nucleos(t)ide analogue combination therapy in chronic hepatitis B infection. Alimentary pharmacology \& therapeutics. 2016;44(7):653-61.

10.Al Ashgar H, Peedikayil MC, Al Quaiz M, Al Sohaibani F, Al Fadda A, Khan MQ, et al. HBsAg clearance in chronic hepatitis $B$ patients with add-on pegylated interferon alfa-2a to ongoing tenofovir treatment: A randomized controlled study. Saudi journal of gastroenterology: official journal of the Saudi Gastroenterology Association. 2017;23(3):190-

11.Wei W, Wu Q, Zhou J, Kong Y, You H. A Better Antiviral Efficacy Found in Nucleos(t)ide Analog (NA) Combinations with Interferon Therapy than NA Monotherapy for HBeAg Positive Chronic Hepatitis B: A Meta-Analysis. International journal of environmental research and public health. 2015;12(8):10039-55.

12.Zeng W, Yuan J, Liu YX, Zhang Y, Li SX, Yao SM, et al. [Efficacy of Peg-interferon alpha-2a combinated with entecavir on HBeAg positive chronic hepatitis B patients with high serum hepatitis B viral loads]. Zhonghua shi yan he lin chuang bing du xue za zhi = Zhonghua shiyan he linchuang bingduxue zazhi = Chinese journal of experimental and clinical virology. 2013;27(2):115-8.

13.Enomoto M, Tamori A, Nishiguchi S, Kawada N. Combination therapy with a nucleos(t)ide analogue and interferon for chronic hepatitis B: simultaneous or sequential. Journal of gastroenterology. 2013;48(9):999-1005.

14.Matsumoto A, Nishiguchi S, Enomoto H, et al. Combinational use of hepatitis B viral antigens predicts responses to nucleos(t)ide analogue/peg-interferon sequential therapy[J]. J Gastroenterol, 2018, 53(2): 247-257.

15.Wursthorn K, Lutgehetmann M, Dandri M, Volz T, Buggisch P, Zollner B, et al. Peginterferon alpha-2b plus adefovir induce strong cccDNA decline and HBsAg reduction in patients with chronic hepatitis B. Hepatology. 2006;44(3):675-84.

16.Lampertico P. The royal wedding in chronic hepatitis B: The haves and the have-nots for the combination of pegylated interferon and nucleos(t)ide therapy. Hepatology. 2015;61(5):1459-61.

17.Ning Q, Han M, Sun Y, Jiang J, Tan D, Hou J, Tang H, Sheng J, Zhao M. Switching from entecavir to PegIFN alfa-2a in patients with HBeAg-positive chronic hepatitis B: a randomised open-label trial (OSST trial). Journal of hepatology 2014; 61(4): 777-84.

18.Hu P, Shang J, Zhang W, Gong G, Li Y, Chen X, Jiang J, Xie Q, Dou X, Sun Y. 0116: Predictive value of baseline and ontreatment qHBsAg level in HBeAg positive CHB patients who switched from NUCs to pegylated interferon A-2A: A further analysis from new switch study. Journal of hepatology 2015; 62: S251-S.

19.Hu P, Shang J, Zhang W, et al. HBsAg Loss with Peg-interferon Alfa-2a in Hepatitis B Patients with Partial Response to Nucleos(t)ide Analog: New Switch Study. Journal of clinical and translational hepatology, 2018, 6(1): 25-34.

20.Tang LSY, Covert E, Wilson E, et al. Chronic Hepatitis B Infection: A Review. Jama, 2018, 319(17): 1802-1813.. 
21.Ouzan D, Penaranda G, Joly H, Khiri H, Pironti A, Halfon P. Add-on peg-interferon leads to loss of HBsAg in patients with HBeAg-negative chronic hepatitis and HBV DNA fully suppressed by long-term nucleotide analogs. Journal of clinical virology: the official publication of the Pan American Society for Clinical Virology. 2013;58(4):713-7.

22. Li GJ, Yu YQ, Chen SL, Fan P, Shao LY, Chen JZ, Li CS, Yi B, Chen WC, Xie SY, Mao XN, Zou HH, Zhang WH. Sequential combination therapy with pegylated interferon leads to loss of hepatitis B surface antigen and hepatitis $B$ e antigen (HBeAg) seroconversion in HBeAg-positive chronic hepatitis B patients receiving long-term entecavir treatment. Antimicrobial agents and chemotherapy 2015; 59(7): 4121-8.

23.Brouwer WP, Xie Q, Sonneveld MJ, Zhang N, Zhang Q, Tabak F, et al. Adding pegylated interferon to entecavir for hepatitis $B$ e antigen-positive chronic hepatitis B: A multicenter randomized trial (ARES study). Hepatology. 2015;61(5):1512-22.

24.Wang Y, Zhang Z, Ji D, Chen GF, Feng X, Gong LL, et al. Regulation of T cell function by microRNA-720. Scientific reports. 2015;5:12159.

25.Tachi Y, Hirai T, Ishizu Y, Honda T, Kuzuya T, Hayashi K, et al. alpha-fetoprotein levels after interferon therapy predict regression of liver fibrosis in patients with sustained virological response. Journal of gastroenterology and hepatology. 2016;31(5):1001-8.

26. Bourliere M, Rabiega P, Ganne-Carrie N, Serfaty L, Marcellin P, Barthe Y, et al. Effect on HBs antigen clearance of addition of pegylated interferon alfa- 2 a to nucleos(t)ide analogue therapy versus nucleos(t)ide analogue therapy alone in patients with $\mathrm{HBe}$ antigen-negative chronic hepatitis B and sustained undetectable plasma hepatitis B virus DNA: a randomised, controlled, open-label trial. The lancet Gastroenterology \& hepatology. 2017;2(3):177-88.

27. de Niet A, Jansen L, Stelma F, Willemse SB, Kuiken SD, Weijer S, et al. Peg-interferon plus nucleotide analogue treatment versus no treatment in patients with chronic hepatitis B with a low viral load: a randomised controlled, openlabel trial. The lancet Gastroenterology \& hepatology. 2017;2(8):576-84.

28. Udompap P, Kim D, Ahmed A, et al. Longitudinal trends in renal function in chronic hepatitis B patients receiving oral antiviral treatment[J]. Aliment Pharmacol Ther, 2018, 48(11-12): 1282-1289.

\section{Tables}

Table 1. Baseline clinical data of the two study groups 


\begin{tabular}{|c|c|c|c|}
\hline Variables & NAs monotherapy $(\mathrm{n}=56)$ & $\begin{array}{l}\text { Combination } \\
\text { Therapy }(n=73)\end{array}$ & $P$ value \\
\hline Age(Year) & $45.5 \pm 12.7$ & $42.9 \pm 12.2$ & 0.489 \\
\hline Male $\square \% \square$ & $35 \square 62.5 \% \square$ & $48 \square 65.75 \% \square$ & 0.367 \\
\hline BMI & $23.1 \pm 3.1$ & $23.4 \pm 2.9$ & 0.536 \\
\hline $\mathrm{ALT} \square \mathrm{U} / \mathrm{L} \square$ & $79.5 \pm 64.9$ & $92.4 \pm 104.2$ & 0.447 \\
\hline $\mathrm{AST} \square \mathrm{U} / \mathrm{L} \square$ & $60.8 \pm 38.9$ & $69.1 \pm 66.7$ & 0.435 \\
\hline TBiløumol/L $\square$ & $14.5 \pm 6.9$ & $14.8 \pm 8.8$ & 0.791 \\
\hline $\mathrm{AFP} \square \mathrm{ng} / \mathrm{ml} \square$ & $23.4 \pm 77.3$ & $33.3 \pm 96.9$ & 0.839 \\
\hline Liver stiffness & $20.0 \pm 13.4$ & $17.2 \pm 13.2$ & 0.323 \\
\hline $\operatorname{PLT} \square 10^{\wedge} 9 / \mathrm{L} \square$ & $127.3 \pm 50.8$ & $122.8 \pm 53.1$ & 0.643 \\
\hline HBV DNA $\rrbracket \log _{10} \mathrm{IU} / \mathrm{ml} \square$ & $5.68 \pm 1.23$ & $5.56 \pm 1.44$ & 0.636 \\
\hline HBeAg positive & $28 \square 50 \% \square$ & $32 \llbracket 43.8 \% \square$ & 0.612 \\
\hline
\end{tabular}

Data are shown as the mean \pm standard deviation (SD) or $\mathrm{n}(\%)$ and they were compared using the independent-sample test or a chi-square test.

Abbreviations: BMI, Body Mass Index; ALT, alanine aminotransferase; AST, aspartate aminotransferase; TBil, total bilirubin; AFP, alpha-fetoprotein; PLT, platelet; HBeAg, hepatitis B e surface antigen

Table 2. On-treatment laboratory examination comparative results at different time points between the two groups

\begin{tabular}{|c|c|c|c|c|c|c|c|c|c|c|}
\hline \multirow[t]{2}{*}{ Variable } & \multirow[t]{2}{*}{ group } & \multirow[t]{2}{*}{ Baseline } & 26 & \multirow[t]{2}{*}{$P$} & \multirow{2}{*}{$\begin{array}{l}52 \\
\text { weeks } \\
\end{array}$} & \multirow[t]{2}{*}{$P$} & \multirow{2}{*}{$\begin{array}{l}78 \\
\text { weeks } \\
\end{array}$} & \multirow[t]{2}{*}{$P$} & \multirow{2}{*}{$\begin{array}{c}104 \\
\text { Weeks }\end{array}$} & \multirow[t]{2}{*}{$P$} \\
\hline & & & weeks & & & & & & & \\
\hline \multirow[t]{2}{*}{$\mathrm{ALT} \square \mathrm{U} / \mathrm{L} \square$} & monotherapy & $79.5 \pm 64.9$ & $30.5 \pm 16.1$ & 0.927 & $26.0 \pm 12.1$ & $0.029 *$ & $24.4 \pm 9.5$ & 0.158 & $24.8 \pm 11.5$ & 0.2 \\
\hline & Add on & $92.4 \pm 104.2$ & $30.8 \pm 17.6$ & & $37.4 \pm 34.4$ & & $29.9 \pm 24.6$ & & $40.1 \pm 62.7$ & \\
\hline \multirow[t]{2}{*}{$\mathrm{AST} \square \mathrm{U} / \mathrm{L} \square$} & monotherapy & $60.8 \pm 38.9$ & $31.2 \pm 16.1$ & 0.956 & $26.8 \pm 7.0$ & $0.007^{*}$ & $25.8 \pm 6.2$ & 0.108 & $25.4 \pm 7.5$ & 0.403 \\
\hline & Add on & $69.1 \pm 66.7$ & $31.3 \pm 13.1$ & & $36.4 \pm 23.6$ & & $29.3 \pm 13.7$ & & $28.5 \pm 18.2$ & \\
\hline \multirow[t]{2}{*}{$\operatorname{ALB}(g / L)$} & monotherapy & $46.8 \pm 5.5$ & $45.3 \pm 2.9$ & 0.799 & $45.3 \pm 2.1$ & 0.208 & $46.5 \pm 4.3$ & 0.91 & $48.2 \pm 4.7$ & 0.774 \\
\hline & Add on & $42.5 \pm 4.9$ & $45.4 \pm 3.8$ & & $44.4 \pm 4.3$ & & $45.1 \pm 4.1$ & & $47.8 \pm 6.3$ & \\
\hline \multirow[t]{2}{*}{ TBil(umol/L) } & monotherapy & $14.5 \pm 6.9$ & $14.3 \pm 5.4$ & 0.781 & $15.9 \pm 7.0$ & 0.649 & $14.3 \pm 5.5$ & 0.292 & $20.6 \pm 32.7$ & 0.143 \\
\hline & Add on & $14.8 \pm 8.8$ & $14.0 \pm 6.2$ & & $18.4 \pm 38.6$ & & $13.2 \pm 5.8$ & & $12.4 \pm 5.0$ & \\
\hline \multirow[t]{2}{*}{$\mathrm{AFP}(\mathrm{ng} / \mathrm{ml})$} & monotherapy & $23.4 \pm 77.3$ & $3.5 \pm 1.7$ & 0.221 & $3.3 \pm 2.8$ & 0.058 & $2.4 \pm 0.84$ & $0.011 *$ & $2.4 \pm 0.9$ & 0.07 \\
\hline & Add on & $33.3 \pm 96.9$ & $6.8 \pm 19.1$ & & $4.4 \pm 3.2$ & & $4.7 \pm 5.7$ & & $4.3 \pm 5.5$ & \\
\hline Liver & monotherapy & $20.0 \pm 13.4$ & $12.9 \pm 7.9$ & 0.853 & $12.3 \pm 8.3$ & 0.195 & $11.1 \pm 10.7$ & 0.357 & $12.8 \pm 13.9$ & $0.037 *$ \\
\hline stiffness & Add on & $17.2 \pm 13.2$ & $13.3 \pm 12.4$ & & $10.5 \pm 5.9$ & & $9.5 \pm 5.9$ & & $7.5 \pm 3.4$ & \\
\hline HBV DNA & monotherapy & $5.68 \pm 1.23$ & $3.07 \pm 0.94$ & 0.759 & $3.11 \pm 0.41$ & 0.552 & & & 1 & I \\
\hline$\left(\log _{10} \mathrm{IU} / \mathrm{ml}\right)$ & Add on & $5.56 \pm 1.44$ & $3.01 \pm 0.48$ & & $2.95 \pm 0.04$ & & & & 1 & \\
\hline
\end{tabular}

Note: Data were mean \pm SD and were compared by Independent-Sample Test. *: P value of $<0.05$ was defined as statistically significant. Monotherapy means that patients in this group only received ETV treatment. Add on means that patients in this group 
received add-on pegylated interferon alfa-2a to ongoing ETV treatment. There were few patients HBV DNA viral load > 500 $\mathrm{IU} / \mathrm{ml}$ at week 78 and week $104 \llbracket$ so the data was not comparable.

Table 3. Clinical efficacy at baseline and at the end of the study in each group

\begin{tabular}{|c|c|c|c|c|c|c|}
\hline \multirow[t]{2}{*}{ Variable } & \multicolumn{2}{|c|}{ monotherapy } & \multirow[t]{2}{*}{$P$} & \multicolumn{2}{|c|}{ combination therapy } & \multirow[t]{2}{*}{$P$} \\
\hline & Baseline & 2years & & Baseline & 2years & \\
\hline $\mathrm{ALT} \square \mathrm{U} / \mathrm{L} \square$ & $79.5 \pm 64.9$ & $24.8 \pm 11.5$ & 0.000 & $92.4 \pm 104.2$ & $40.1 \pm 62.7$ & 0.007 \\
\hline $\mathrm{AST} \square \mathrm{U} / \mathrm{L} \square$ & $60.8 \pm 38.9$ & $25.4 \pm 7.5$ & 0.000 & $69.1 \pm 66.7$ & $28.5 \pm 18.2$ & 0.001 \\
\hline $\operatorname{ALB}(g / L)$ & $46.8 \pm 5.5$ & $48.2 \pm 4.7$ & 0.32 & $42.5 \pm 4.9$ & $47.8 \pm 6.3$ & 0.000 \\
\hline TBiløumol/L】 & $14.5 \pm 6.9$ & $20.6 \pm 32.7$ & 0.207 & $14.8 \pm 8.8$ & $12.4 \pm 5.0$ & 0.142 \\
\hline $\mathrm{AFP} \llbracket \mathrm{ng} / \mathrm{ml} \square$ & $23.4 \pm 77.3$ & $2.4 \pm 0.91$ & 0.149 & $33.3 \pm 96.9$ & $4.3 \pm 5.5$ & 0.085 \\
\hline Liver stiffness & $20.0 \pm 13.4$ & $12.8 \pm 13.9$ & 0.035 & $17.2 \pm 13.2$ & $7.5 \pm 3.4$ & 0.000 \\
\hline HBV viral load & $5.68 \pm 1.23$ & $<500$ & $<0.05$ & $5.56 \pm 1.44$ & $<500$ & $<0.05$ \\
\hline \multicolumn{7}{|l|}{ Liver histology } \\
\hline Inflammation grades & $2 \square 2,3 \square$ & $1 \square 1,1 \square$ & 0.000 & $2 \square 2,3 \square$ & $1 \square 1,1.25 \square$ & 0.001 \\
\hline Fibrosis stage & $3 \square 2,4 \square$ & $1.5 \square 1,3 \square$ & 0.021 & $3 \square 2,4 \square$ & $1.5 \square 1,3.25 \square$ & 0.011 \\
\hline Ishak fibrosis score & $4 \llbracket 1,4 \square$ & $2 \square 1,3.75 \square$ & 0.47 & $4 \llbracket 3,4 \square$ & $1.5 \square 1,3.25 \square$ & 0.001 \\
\hline
\end{tabular}

Note: All data are presented as the mean \pm SD, or median (IQR: 1st, 3rd quartiles) as appropriate. *P value of $<0.05$ was defined as statistically significant.

Table 4. The number of patients who had HBsAg, HBeAg clearance, and/or seroconversion with emerging antibody during the research period

\begin{tabular}{lllllll}
\hline Variable & group & 0 & 26 & 52 & 78 & 104 \\
& & & & & & \\
HBsAg lost & monotherapy & 0 & 0 & 1 & 1 & 1 \\
& Add on & 0 & 0 & 0 & 1 & 3 \\
HBsAb acquire & monotherapy & 0 & 0 & 1 & 1 & 1 \\
& Add on & 0 & 0 & 3 & 3 & 3 \\
HBeAg lost & monotherapy & 0 & 1 & 4 & 5 & 7 \\
\multirow{2}{*}{ HBeAb acquire } & Add on & 0 & 2 & 5 & 6 & 8 \\
& monotherapy & 0 & 1 & 4 & 4 & 6 \\
& Add on & 0 & 1 & 4 & 5 & 7 \\
\hline
\end{tabular}

Note: Data are presented as the number of patients.

\section{Figures}


A

\begin{tabular}{|c|c|c|c|c|c|}
\hline & ETV & ETV & ETV & ETV & monotherapy \\
\hline \multirow{3}{*}{$\begin{array}{c}\text { Long- term } \\
\text { nucleos analogue }\end{array}$} & \multicolumn{2}{|c|}{26} & 52 & 104 & week \\
\hline & ETV & ETV+IFN & ETV & ETV & $\begin{array}{l}\text { Combination } \\
\text { therapy }\end{array}$ \\
\hline & & & & & Neek \\
\hline
\end{tabular}

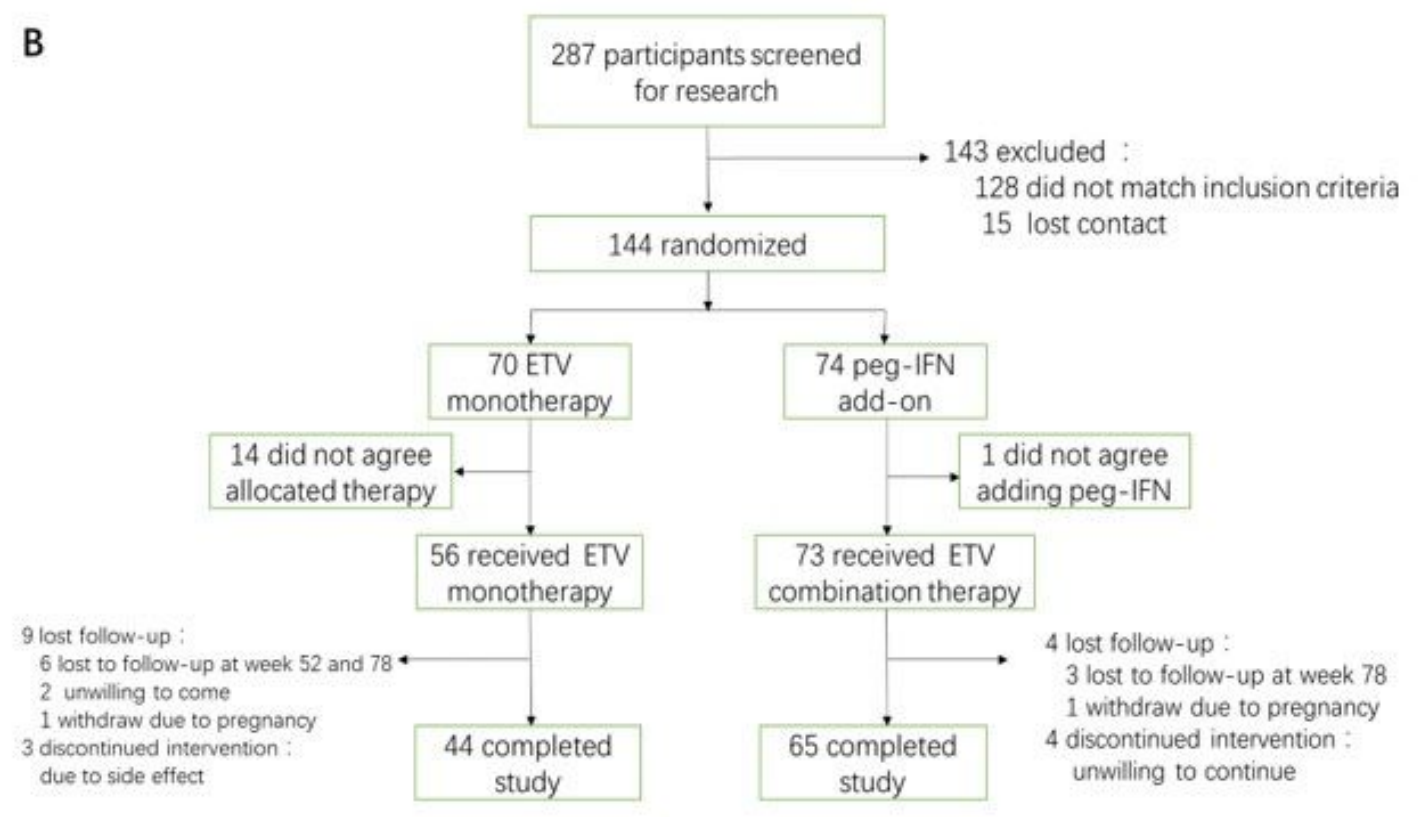

Figure 1

A: Trial design. Combination therapy adding on pre-IFN-a-2a from weeks 26 to 52 . All patients were followed-up at least for 104 weeks. B: Flowchart showing the disposition of patients during the research.

A

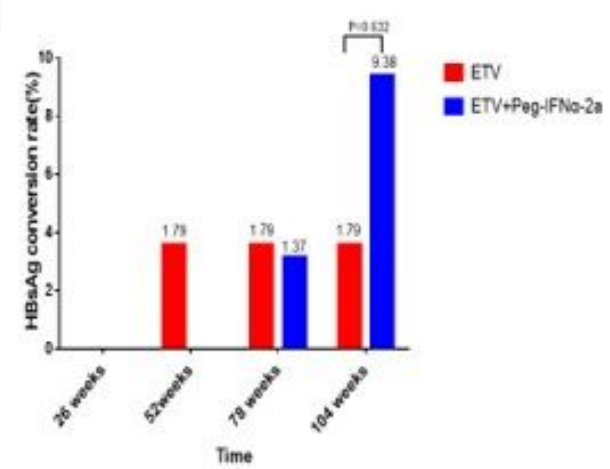

C

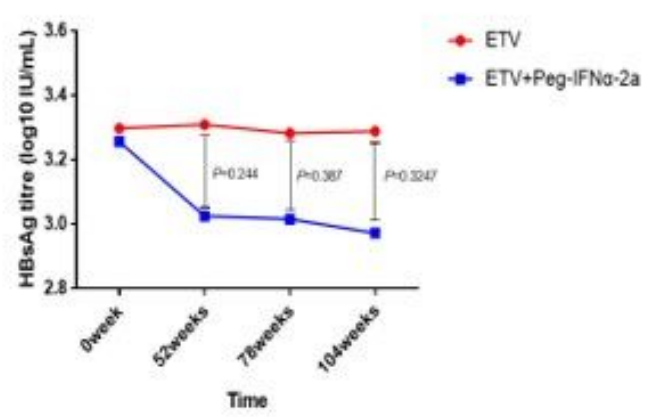

B

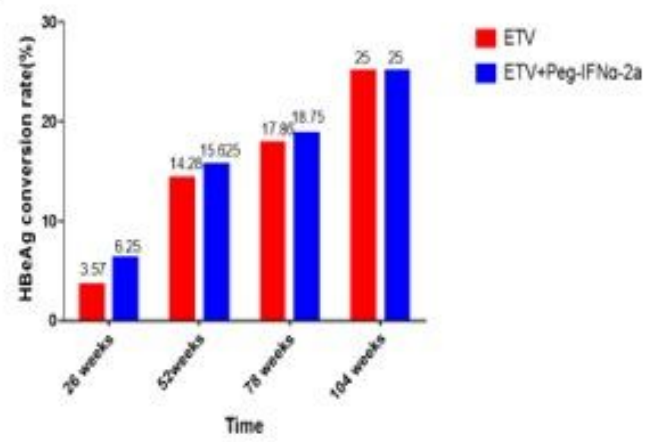

$\mathrm{D}$

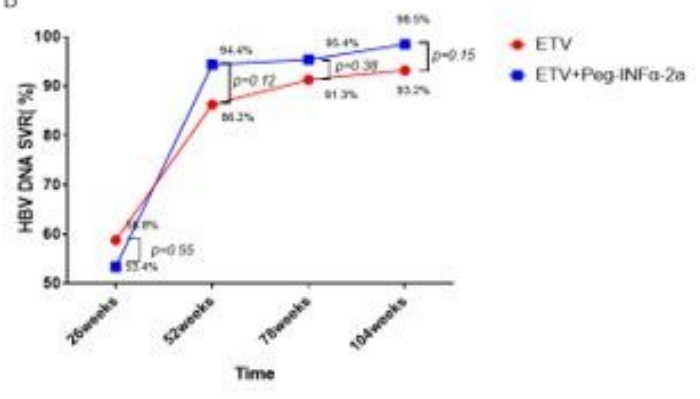

Figure 2 
A/B:The rate of patients who had HBsAg, HBeAg clearance and/or seroconversion with respective antibody formation. C: The change in HBsAg levels during treatment in both groups. D: Sustained virologic response (SVR) at different time points. There was no significant difference in the HBsAg/HBeAg conversion rate, HBsAg levels and SVR between two groups at the end of the trial. But there is a tendency that combination therapy has a lower HBsAg levels than ETV monotherapy.

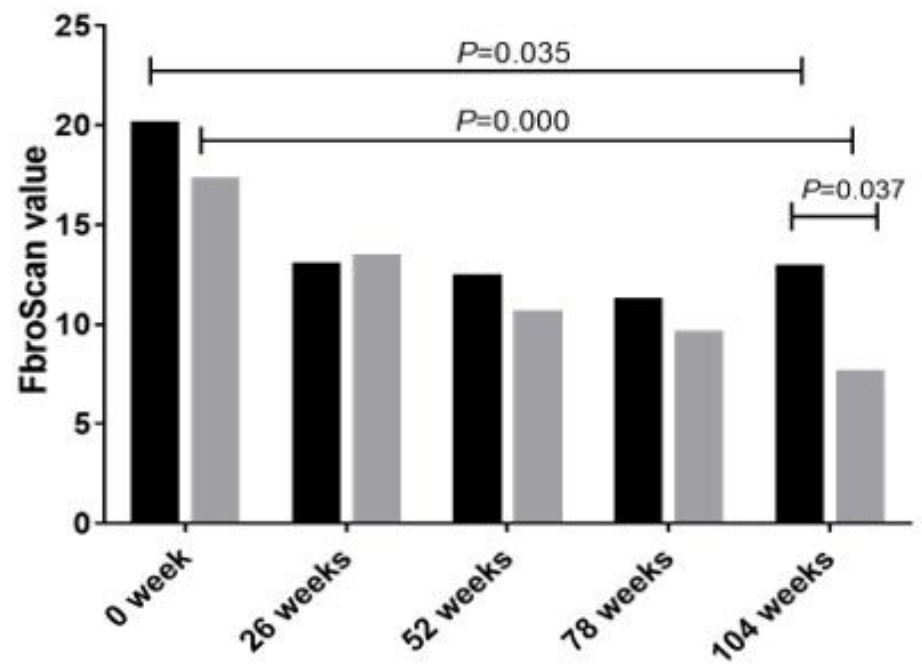

\author{
ETV \\ ETV+Peg-IFNa-2a
}

\title{
Figure 3
}

The transient elastography value is presented as the mean and standard deviation (SD). $\mathrm{P}<0.05$ indicates a significant difference.

\section{ETV}

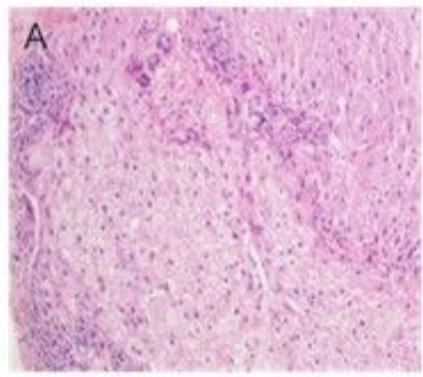

104 weeks

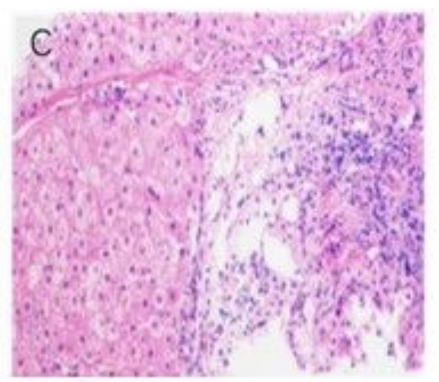

$$
\text { ETV+Peg-IFN } \alpha-a
$$
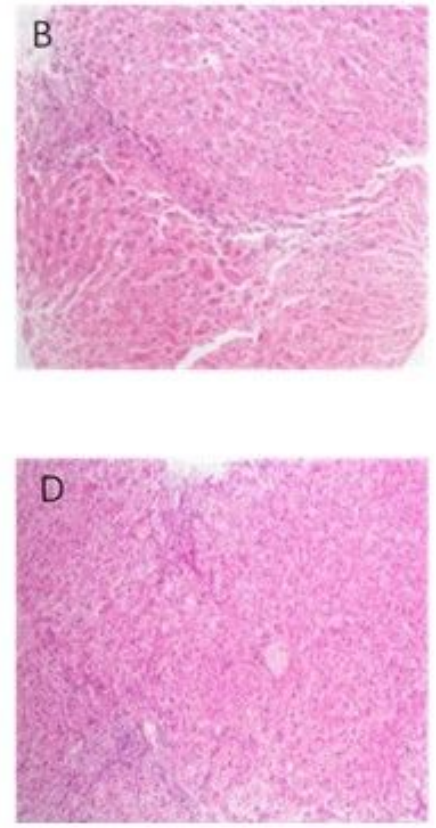

\section{Figure 4}

Liver biopsy examination results (magnification $\times 100$ ) A. Histological examination results of the liver indicated inflammation grade 1 and fibrosis stage 2 in an ETV monotherapy group patient before treatment. B. Histologic 
examination results of the liver indicated inflammation grade 2 and fibrosis stage 2 , in an ETV+ pre-IFN-a-2a group patient before treatment. C. Second liver biopsy in the same patient in the ETV monotherapy group after 2 years of treatment. The results indicate inflammation grade 1 and fibrosis stage 1. D. Second liver biopsy of the same patient in the ETV+ pre-IFN-a-2a group after 2 years of treatment. The results indicate inflammation grade 1 and fibrosis stage 1.

\section{Supplementary Files}

This is a list of supplementary files associated with this preprint. Click to download.

- supplement1.docx

- supplement2.doc 